\title{
Development of hydrophobic metakaolin hollow fibre membrane for membrane distillation application
}

\author{
Siti Khadijah Hubadillah, Mohd Hafiz Dzarfan Othman*, Tai Zhong Sheng, Ahmad Fauzi Ismail, \\ Mukhlis A Rahman, Juhana Jaafar
}

Advanced Membrane Technology Research Centre (AMTEC), Faculty of Chemical and Energy Engineering, Universiti Teknologi Malaysia, 81310 Skudai, Johor, Malaysia

* Corresponding author: hafiz@petroleum.utm.my

\section{Article history \\ Received 5 May 2018 \\ Revised 1 June 2018 \\ Accepted 2 July 2018 \\ Published Online 25 August 2019 \\ Graphical abstract

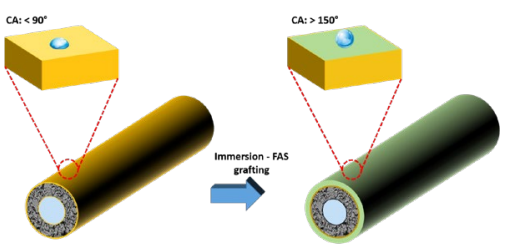

\begin{abstract}
Metakaolin hollow fibre membranes (MHFM) was prepared by a combined phase inversion and sintering method for direct contact membrane distillation (DCMD) application. Four hydrophobic metakaolin hollow fibre membranes (h-MHFM) sintered at different temperatures $\left(1200^{\circ} \mathrm{C}\right.$ to $\left.1500^{\circ} \mathrm{C}\right)$ were successfully prepared by grafting $1 \mathrm{H}, 1 \mathrm{H}, 2 \mathrm{H}, 2 \mathrm{H}$-perfluorodecyltriethoxysilane on the MHFM. Prior to the grafting process, the MHFM was hydrolysed with a mixture of ethanol and water with the ratio of $1: 2$ for 24 hours. The effectiveness of the hydrophobization on each MHFM was assessed using contact angle measurement, scanning electron microscopy (SEM) and three-point bending test. It was found that the increasing sintering temperature improved the mechanical strength from 117.6 MPa to 182.3 MPa. Further increment in mechanical strength was also observed after the modification with fluoroalkylsilane (FAS). The contact angle of the membrane was enhanced up to $120^{\circ}$ after modification. In general, the membrane prepared at low sintering temperature of $1200^{\circ} \mathrm{C}$ exhibited the highest DCMD performance with the water vapor flux of $17.5 \mathrm{~kg} / \mathrm{m}^{2} \mathrm{~h}$ due to the sufficient pore size for the vapor to pass through the membrane structure.
\end{abstract}

Keywords: Ceramic membrane, metakaolin, perfluorodecyltriethoxysilane, hydrophobic

\section{INTRODUCTION}

In recent years, a great deal of research has been devoted to the development of membrane separation technology. Membrane separation is known as a "worldwide technology" especially in water treatment applications due to several advantages such as cost effective, simple operation, long-life term and less energy consuming [1]. Nowadays, hydrophobic membranes such as polyvinylidene fluoride (PVDF), polytetrafluoroethylene (PTFE), and polypropylene (PP) have received wide attention in advanced membrane separation technologies, including membrane distillation (MD). Munirasu et al. (2017) prepared the superhydrophobic PVDF membranes via phase inversion for the MD application [2]. The membrane exhibited high contact angle value of $164^{\circ}$ and mean pore size in the range of 0.1 to $0.3 \mu \mathrm{m}$. A high salt rejection of $99.999 \%$ with $80 \mathrm{LMH}$ flux were obtained. Zhang et al. (2016) modified the PVDF membranes with fluorographite for seawater desalination using direct contact membrane distillation (DCMD) [3]. The FESEM images showed that the fluorographite particles were randomly located on the modified membrane which enhanced the contact angle value from $109^{\circ}$ to $122^{\circ}$. Interestingly, the liquid entry pressure $\left(\mathrm{LEP}_{\mathrm{w}}\right)$ was also enhanced from 0.9 to 1.3 bar. Recently, Zhang et al. (2016) evaluated the desalination performance of the commercial PTFE membranes through vacuum membrane distillation (VMD) [3]. The commercial PTFE membranes were supplied by three different companies, and exhibited the contact angles of $136.1^{\circ}$ to $145.9^{\circ}, \mathrm{LEP}_{\mathrm{w}}$ of 3.2 to 3.6 bar and mean pore sizes of 0.1052 to $0.1495 \mu \mathrm{m}$.

MD is a membrane separation process in which two solutions of different temperatures are separated by a hydrophobic porous membrane [4]. The hot water at the feed side vaporizes and passes through the membrane pores. The vapor then condenses at the cold side of the membrane as pure permeate [5]. Fig. 1 shows the schematic diagram of the MD mechanism. The feed temperature drops across the boundary layer adjoining the membrane surface at the feed side. Thereby, the feed water vaporizes, and the vapor transports through the hydrophobic membrane pores to the permeate side. Simultaneously, the heat also transports through the hydrophobic membrane to the cold permeate side. This mechanism is called as heat transfer. There are two steps involved during heat transfer:

1. Heat transfers as sensible heat and latent heat, which creates the temperature difference between the boundary layer and bulk flow.

2. Heat transfers from the bulk flow of the hot feed side to the boundary layer through heat convection.

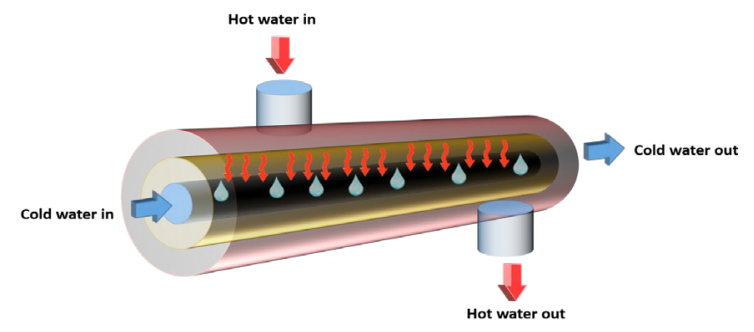

Fig. 1 Schematic diagram of MD mechanism

However, the long-term performance of the polymeric membranes has been doubted due to their weak endurance towards harsh operating conditions [6]. For example, the sensitivity towards high temperature or swelling phenomenon of the polymeric membranes 
results in short working life. Whereas, ceramic membranes show excellent resistance towards temperature, pressure and chemical. This opens up the possibility of using ceramic membranes for treating various feed solutions at different operating conditions [7, 8] Unfortunately, ceramic membranes cannot be used directly for MD due to their hydrophilicity nature. The modification of the hydrophilic ceramic membrane into hydrophobic has widely been reported Krajewski et al. (2006) modified the commercial tubular zirconia membranes with alumina support using $1 \mathrm{H}, 1 \mathrm{H}, 2 \mathrm{H}, 2 \mathrm{H}-$ perfluorodecyltriethoxysilane at various soaking times [9]. After modification, the contact angles were in the range of $142^{\circ}$ to $148^{\circ}$. Huang et al. (2016) applied a similar grafting process on alumina flat sheet membrane and successfully modified the hydrophilic ceramic membrane into hydrophobic with the contact angle of $158^{\circ}$ [10]. However, it is worth to mention that these commercial membranes were fabricated using the expensive starting materials (alumina, zirconia, etc.) and require high sintering temperature, making them less cost competitive. Accordingly, low-cost ceramic membranes derived from clay have been developed and modified for the MD applications. For instance, Khemakhem et al. (2011) developed a novel ceramic membrane from Tunisian clay and modified the membrane with triethoxy-1H,1H,2H,2H-per-fluorodecylsilane [11].

Due to the superior advantages of ceramic membranes for MD application, the development of cost competitive ceramic membranes is critically in need. Hence, this study aims to develop a low-cost hydrophobic ceramic membrane for MD application. In our previous work [12], we studied the development of the high strength and lowcost metakaolin ceramic hollow fibre membrane at various sintering temperatures ranging from $1200^{\circ} \mathrm{C}$ to $1500^{\circ} \mathrm{C}$. However, the prepared membrane was hydrophilic, hence, not suitable to use for MD application. Therefore, in this study, the metakaolin hollow fibre membrane was hydrophobized with fluoroalkylsilanes (FAS). The properties of the modified membranes were determined and tested for MD application.

\section{EXPERIMENTAL}

\section{Materials}

Metakaolin was produced through the calcination of kaolin powder (purchased from Bg Oil Chem Sdn Bhd, Penang, Malaysia) at $700^{\circ} \mathrm{C}$ for 3 hours. Polyethersulfone (PESf, Radel A-300, Ameco Performance, USA), N-methyl-2-pyroolidone (NMP, QRëC ${ }^{\mathrm{TM}}$ ) and Arlacel P135 (polyethyleneglycol 30-dipolyhydroxystearate, CRODA) were used as the polymer binder, solvent and dispersant, respectively for the preparation of the ceramic suspension. Tap water was used as the bore fluid and coagulant bath during the fabrication of the ceramic hollow fibre membrane. $1 \mathrm{H}, 1 \mathrm{H}, 2 \mathrm{H}, 2 \mathrm{H}-$ perfluorodecyltriethoxysilane $(97 \%)$, which has the chemical formula of $\mathrm{C}_{8} \mathrm{~F}_{17} \mathrm{C}_{2} \mathrm{H}_{4} \mathrm{Si}\left(\mathrm{OC}_{2} \mathrm{H}_{5}\right)_{3}(\mathrm{C} 8)$ was used as the grafting agent (Sigma Aldrich, USA) while ethanol $\left(\mathrm{C}_{2} \mathrm{H}_{5} \mathrm{OH}\right)$ and sodium chloride $(\mathrm{NaCl})$ were purchased from Merck, Germany.

\section{Preparation and modification of metakaolin hollow fibre membrane}

In this study, metakaolin hollow fibre membranes (MHFM) were prepared via phase inversion and sintering technique at various sintering temperatures, as reported in our previous work [12]. Prior to the fabrication process, a ceramic suspension consisting of metakaolin as ceramic material, dispersant, binder and solvent was prepared. 1 wt $\%$ of Arlacel P135 was added to $49 \mathrm{wt} \%$ of NMP solvent with gentle stirring prior to the addition of metakaolin powder $(45 \mathrm{wt} \%)$. The mixture was then ball milled for 48 hours at $150 \mathrm{rpm} .5 \mathrm{wt} \%$ of PESf was then added to the suspension as binder and the suspension was ball milled for another $48 \mathrm{~h}$. After that, the suspension was degassed for 1 hour and immediately transferred into a stainless-steel syringe. Table 1 shows the fabrication conditions of MHFM. After extrusion, the MHFM precursors were soaked in water overnight to remove the residual solvents followed by drying in oven. Finally, the precursors were sintered in a high-temperature tubular furnace (XY1700 MAGNA) under air atmosphere. During sintering, the temperature was increased from room temperature to $600^{\circ} \mathrm{C}$ at a heating rate of $2{ }^{\circ} \mathrm{C} / \mathrm{min}$. The temperature was then kept constant for 2 hours to remove the polymer binder. Subsequently, the temperature was further increased to the desired temperature at a rate of $3{ }^{\circ} \mathrm{C} / \mathrm{min}$ and held for 3 hours. Finally, the temperature was cooled down to room temperature at a rate of $5{ }^{\circ} \mathrm{C} / \mathrm{min}$. Prior to grafting, the membranes were rinsed with a solution of distilled water and ethanol in the ratio of $2: 1$ followed by drying at $100^{\circ} \mathrm{C}$ in an oven. Then, the MHFMs were immersed in the grafting solution containing $2 \mathrm{wt} \%$ of FAS and $98 \mathrm{wt} \%$ of ethanol for 24 hours. After that, the MHFMs were rinsed with distilled water and dried in oven before assembling into membrane module. The hydrophobic metakaolin hollow fibre membranes were denoted as h-MHFM.

Table 1 Dope composition and spinning condition.

\begin{tabular}{lc}
\hline \multicolumn{2}{c}{ Dope composition (wt\%) } \\
\hline Metakaolin powder & 45 \\
N-methyl-2-pyrrolidone (NMP) & 49 \\
Polyethersulfone (PESf) & 5 \\
Arlacel & 1 \\
\hline \multicolumn{1}{c}{ Spinning parameters } \\
\hline Bore fluid & Tap water \\
Coagulant fluid & Tap water \\
Bore fluid flow rate (mL/min) & 10 \\
Air gap (cm) & 5 \\
Spinneret: Outer diameter (mm) & 2 \\
Spinneret: Inner diameter (mm) & 1
\end{tabular}

\section{Characterization of hydrophobic metakaolin hollow fibre membrane}

The surface morphology of MHFM and h-MHFM was studied through scanning electron microscopy (SEM, Hitachi model TM3000, Japan). The contact angles of MHFM and h-MHFM were determined using the contact angle goniometer (CA, OCA 15EC Dataphysics, Germany) with deionized water as the contact liquid. $2 \mu \mathrm{L}$ of water droplet was dropped on the membrane surfaces for the contact angle measurements. The LEP $_{\mathrm{w}}$ of the h-MHFM was also investigated using a permeation system. Prior to the measurement, the h-MHFM was potted on an adaptor and the end of the h-MHFM was sealed with epoxy resin. Then, the water was circulated through the lumen side of the h-MHFM. The system pressure was slowly increased by adjusting the pressure gauge. The experiment was stopped when the first drop of water was seen on the shell side of the membrane. The minimum pressure at which the water started to pass through the membrane was taken as the $\mathrm{LEP}_{\mathrm{w}}$. Three-point bending tests were carried out to determine the mechanical strength of the MHFM and h-MHFM using INSTRON 3342. The mechanical strength $\left(\sigma_{F}\right)$ was calculated using Eq. (1) (Hubadillah et al., 2017a; Hubadillah et al., 2016; Hubadillah et al., 2017b):

$$
\sigma_{F}=\frac{8 F L D_{o}}{\pi\left(D_{o}^{4}-D_{i}^{4}\right)}
$$

where $F$ is the maximum load at which the fracture occurred while $L$, $D_{o}$ and $D_{i}$ are the length of the span $(43 \mathrm{~mm})$, the outer and inner diameters of the hollow fibres, respectively.

\section{Direct contact membrane distillation application}

DCMD tests were carried out on a laboratory-scale setup as illustrated in Fig. 2. The setup consisted of the feed and permeate thermostatic cycles, which were connected to a membrane module. The membrane module was assembled using a brass connector consisting of two tee-shaped and a 3/4" hex nipple connectors. The system was designed to equip with two circulating streams, i.e. the hot stream, also known as feed stream, that circulated through the 
membrane shell-side, and the cold stream that was fed through the lumen-side of the h-MHFM. Deionized water was employed as the feed and permeate. Both solution temperatures were controlled using coiled heater (830, PROTECH) and chiller (S\&A CW-5000 Water chiller), respectively. The feed and permeate solutions were circulated throughout the DCMD process. Four liquid digital thermometers (Extech 392050, Dial Thermometer) were attached on the DCMD system to measure the temperature of the feed and permeate flows. In this study, the feed and permeate temperatures were fixed at $50^{\circ} \mathrm{C}$ and $10^{\circ} \mathrm{C}$, respectively. Meanwhile, the cross-flow velocities of the hot and cold streams were both set at $0.023 \mathrm{~m} / \mathrm{s}$. The permeate flux, $J_{v}$ in the form of water vapor was collected at the permeate tank at which the weight of the tank with permeate was measured using a weighing balance (Model WA-K, WJ) and was then calculated using eq. (3):

$$
J_{V}=\frac{\Delta W}{A \Delta t}
$$

where $\Delta W(\mathrm{~kg})$ is the weight of the permeate water vapor collected over a predetermined time, $t$ (hours) and $A\left(\mathrm{~m}^{2}\right)$ is the effective membrane area

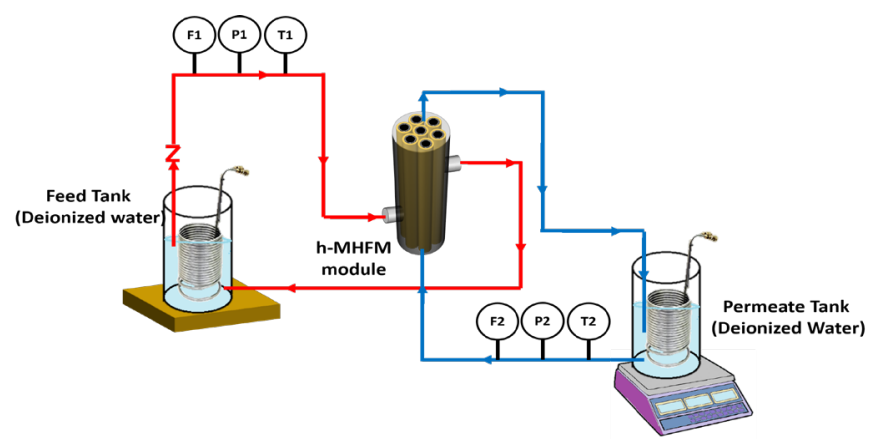

Fig. 2 DCMD setup.

\section{RESULTS AND DISCUSSION}

\section{Microstructure of metakaolin hollow fibre membrane before and after hydrophobization}

Fig. 3 shows the SEM images of the outer surface of the metakaolin hollow fibre membranes before (MHFM) and after modification (h-MHFM) prepared at different sintering temperatures. Two different trends could be observed. Firstly, the surface became denser with the increasing of sintering temperature from $1200^{\circ} \mathrm{C}$ to $1500^{\circ} \mathrm{C}$. This mechanism is widely reported in literatures on the preparation of ceramic membranes at increasing sintering temperatures $[13,14]$. According to Darcovich and Toll (2017), the densification of the ceramic particles in the membrane matrix occurs more rapidly when the sintering temperature increases. As shown in Figure 3 , the densification process began to occur at the sintering temperature of $1300^{\circ} \mathrm{C}$. At the sintering temperature of $1500^{\circ} \mathrm{C}$, the metakaolin particles changed to rod shape, indicating that the metakaolin was converted into mullite. Mullite forms at $1000^{\circ} \mathrm{C}$ due to the crystallographic relation of $\mathrm{Al}-\mathrm{Si}$ spinel phase and metakaolinite, in which the c axis of mullite crystal is parallel to the orientation of the Al-Si spinel phase, where the Al-Si spinel phase requires the collapse of the metakaolinite structure. The mullite growth is accelerated by instantaneous nucleation process and the short distance diffusion [15]. Chakroborty (2016) also stated that this rod-shaped started to develop at the sintering temperature of $950^{\circ} \mathrm{C}$ to $1000^{\circ} \mathrm{C}$ and appeared as cubic with 10 to $60 \mathrm{~nm}$ in sizes.

Secondly, the membrane structure changed after modification with FAS. As observed, the pore size of the MHFM and h-MHFM showed significant changes at the sponge-like region (membrane surface structure) as shown in Fig. 4. A close observation on the SEM images showed that there were nodules forming on the ceramic particles in the membrane matrix. These nodules are the FAS polymer layer attached on the h-MHFM surface after grafting process (Fig. 5).

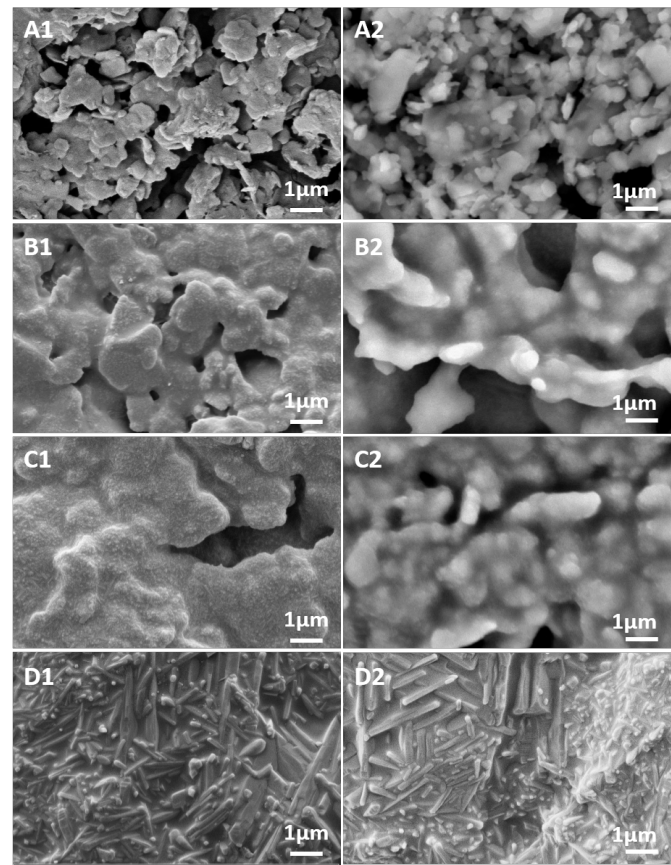

Fig. 3 SEM images of (1) MHFM and (2) h-MHFM prepared at different sintering temperatures; (A) $1200^{\circ} \mathrm{C}$, (B) $1300^{\circ} \mathrm{C}$, (C) $1400^{\circ} \mathrm{C}$, and (D) $1500^{\circ} \mathrm{C}$

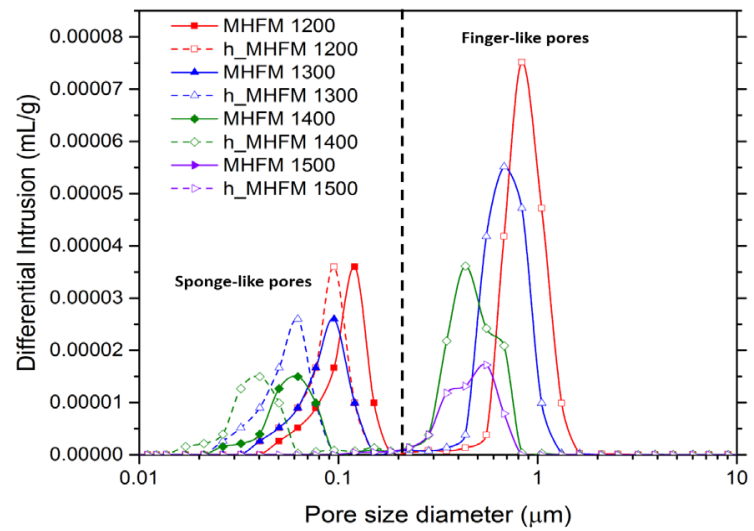

Fig. 4 Pore size distribution of metakaolin hollow fibre membrane prepared at different sintering temperatures before (MHFM) and after grafting (h-MHFM).

Fig. 6 presents the mechanical strength of metakaolin hollow fibre membranes before (MHFM) and after modification (h-MHFM) prepared at different sintering temperatures. As discussed in our previous work [12], the mechanical strength increased with increasing sintering temperature due to the densification mechanism. At the increasing sintering temperatures, the pore size of MHFM reduced which improved the mechanical strength of MHFM. In this study, an improvement of membrane mechanical strength was also observed after surface modification with silane agent (h-MHFM). However, the improvement gap was in between 10 to $20 \mathrm{MPa}$, which was probably due to the formation of polymer layer coated on the surface. For example, for the MHFM and h-MHFM sintered at $1200^{\circ} \mathrm{C}$, the mechanical strength was increased from $117.6 \mathrm{MPa}$ to $122.3 \mathrm{MPa}$. Interestingly, there is no other studies reported on the mechanical strength performance of ceramic membrane before and after surface modification. Therefore, this study offers an advantage by providing the information on the mechanical strength for the ceramic membrane before and after modification. In addition, the enhanced mechanical strength performance also proved that the prepared h-KHFM did not suffer from any crack or defect during the grafting process. 


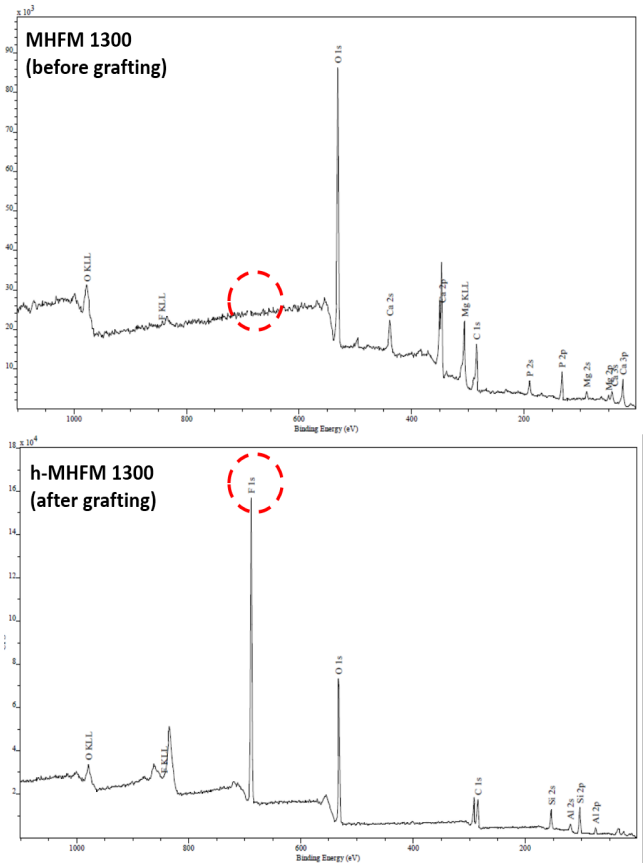

Fig. 5 XPS analysis for h-MHFM sintered at $1300^{\circ} \mathrm{C}$ before and after grafting

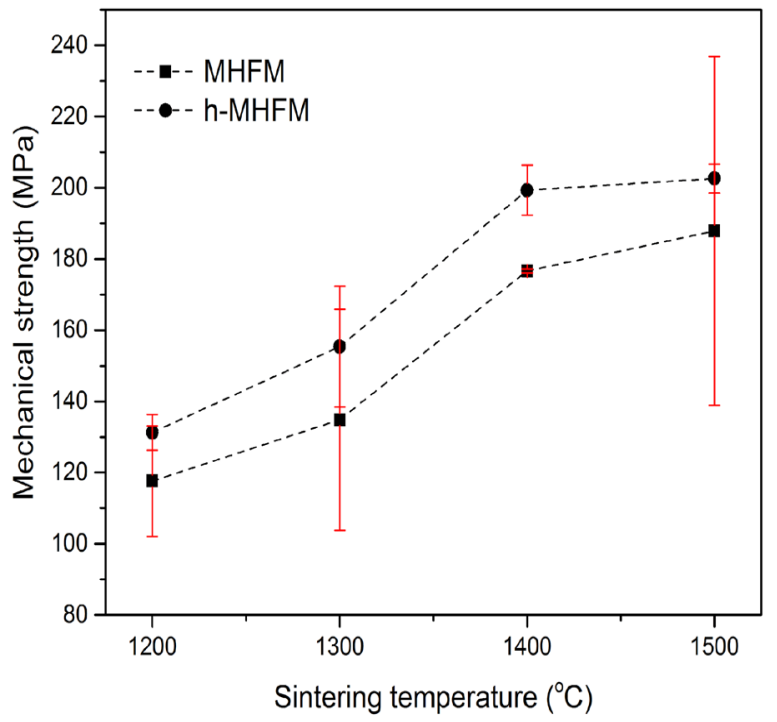

Fig. 6 Mechanical strength results of MHFM and h-MHFM.

\section{Wettability properties of metakaolin hollow fibre membrane before and after modification}

Fig. 7 illustrates the contact angle results for metakaolin hollow fibre membrane before (MHFM) and after modification (h-MHFM). As expected, the contact angle was successfully improved to above $90^{\circ}$. For MHFM, the contact angle showed an increasing trend from $5^{\circ}$ to $39^{\circ}$ at increasing sintering temperatures, indicating the hydrophilic properties of MHFM. After modification, the contact angle demonstrated an increasing trend from $153^{\circ}$ to $165^{\circ}$ at increasing sintering temperatures, but the value was decreased when the sintering temperature was $1500^{\circ} \mathrm{C}$. This was probably due to the rod-shaped surface structure of the h-MHFM that decreased the contact angle value. Figure 8 illustrates the schematic diagram of the water droplet on the h-MHFM prepared at different sintering temperatures. For the membrane sintered at $1500^{\circ} \mathrm{C}$, the contact angle reduced as a result of the flatter surface structure due to the formation of rod-shaped particles as a function of mullitization at higher sintering temperature [16].

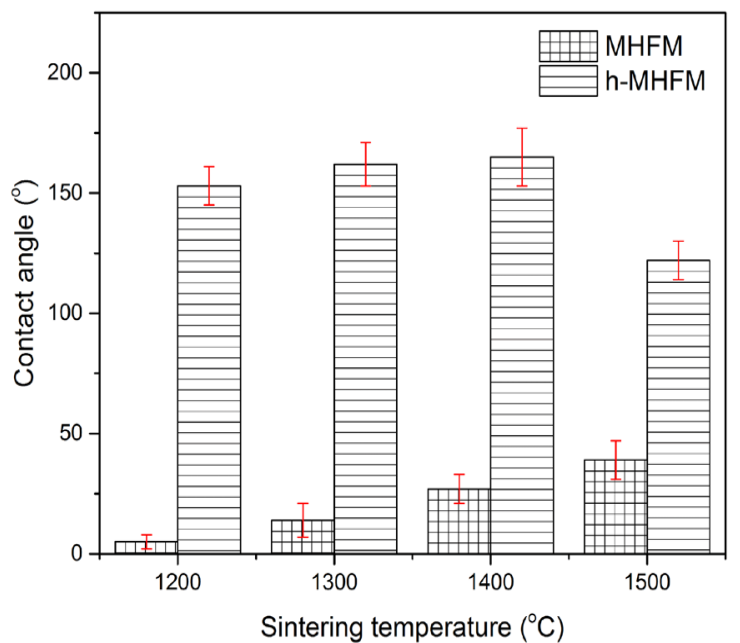

Fig. 7 Contact angles of MHFM and h-MHFM prepared at different sintering temperatures; (A) $1200^{\circ} \mathrm{C},(B) 1300^{\circ} \mathrm{C},(\mathrm{C}) 1400^{\circ} \mathrm{C}$, and (D) $1500^{\circ} \mathrm{C}$.
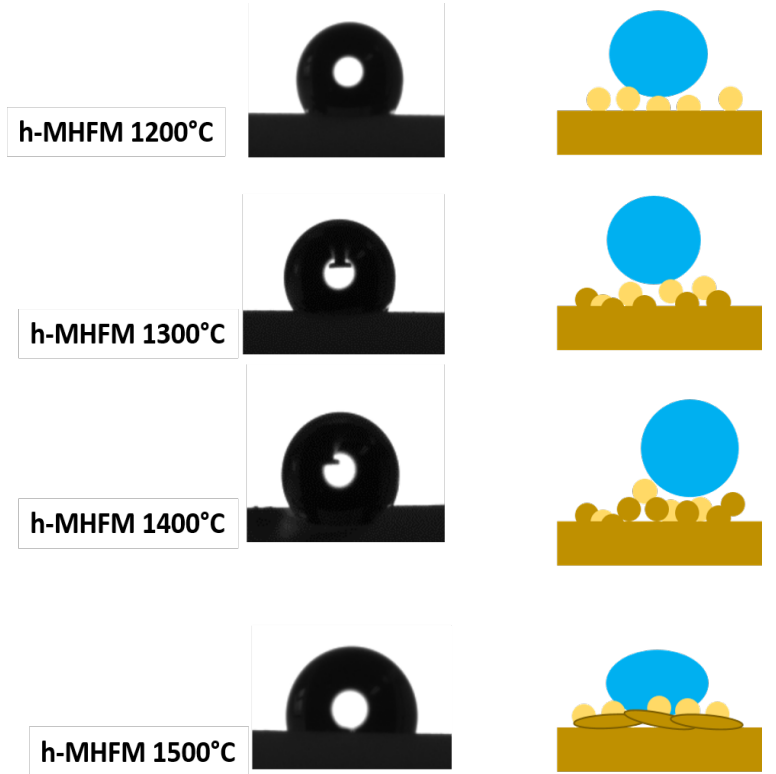

Fig. 8 Schematic diagram for water droplet mechanism on modified membranes.

\section{Direct contact membrane distillation performance}

Fig. 7 shows the DCMD water vapor flux of the modified metakaolin hollow fibre membranes (h-MHFM) for 120 minutes testing period. As can be seen, the h-MHFM sintered at $1200^{\circ} \mathrm{C}$, which exhibited the third highest contact angle, possessed the highest water vapor flux of $17.5 \mathrm{~kg} / \mathrm{m}^{2} \mathrm{~h}$ at the first 10 minutes. The flux started to become stable after 50 minutes with value in range of 16.1 to $16.5 \mathrm{~kg} / \mathrm{m}^{2} \mathrm{~h}$. Increasing sintering temperature would reduce the water vapor flux due to the pore size reduction. At the sintering temperature of $1500^{\circ} \mathrm{C}$, the water vapor flux was the lowest with value in the range of $5.3 \mathrm{~kg} / \mathrm{m}^{2} \mathrm{~h}$. This trend can be explained by the decrease of pore size as the function of sintering temperature. Accordingly, further pore size reduction was observed after grafting (Fig. 4). A similar trend was also observed in a work by $\mathrm{Gu}$ et al. (2016) [7]. In addition, the flux performance of the membranes in this study was lower than that obtained by the polymeric membrane [17]. In this study, it was found that the membrane pore size is also a main factor towards the water vapor flux of MD apart from the membrane hydrophobicity. Future study will be conducted on the use of the prepared h-MHFM for the treatment of contaminated wastewater using MD process. Table 2 shows the comparison of the permeate water vapor flux obtained in this study with literature for DCMD process. 


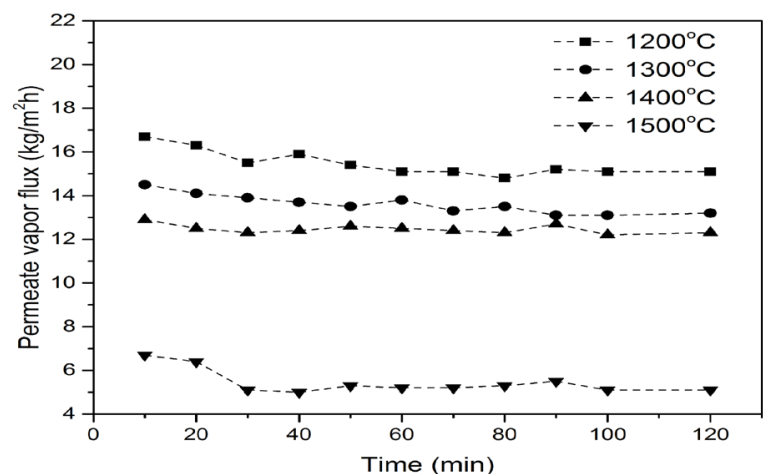

Fig. 9 DCMD water vapor flux for h-MHFM prepared at different sintering temperatures.

Table 2 Comparison of the permeate water vapor flux obtained in this study with literature for DCMD process.

\begin{tabular}{|c|c|c|c|}
\cline { 2 - 4 } \multicolumn{1}{c|}{} & $\begin{array}{c}\text { Type of hollow } \\
\text { fibre membranes }\end{array}$ & $\begin{array}{c}\text { Permeate } \\
\text { water vapor } \\
\text { flux, }\end{array}$ & Ref \\
\hline Polymeric & PVDF-PP & $J_{V} \mathbf{( k g / \mathbf { m } ^ { 2 } \mathbf { h } )}$ & \\
\cline { 2 - 4 } membranes & PTFE & 17.2 & {$[11$} \\
\hline \multirow{3}{*}{ Ceramic } & Beta-Sialon & 12.2 & {$[20]$} \\
\cline { 2 - 4 } membranes & h-MHFM & 16.5 & \\
& 1200 & 13.2 & This \\
& 1300 & 12.9 & work \\
& 1400 & 5.3 & \\
\hline
\end{tabular}

\section{CONCLUSIONS}

Metakaolin hollow fibre membranes at different sintering temperatures were successfully developed and modified to acquire hydrophobic properties for the MD application. The prepared membranes experienced a pore size reduction at increasing sintering temperatures. In addition, the metakaolin particles converted to mullite phase with rod-shaped structure at the sintering temperature of $1500^{\circ} \mathrm{C}$. The modification of the metakaolin hollow fibre membranes with fluoroalkylsilanes successfully converted the membrane into superhydrophobic. Furthermore, the mechanical strength of the metakaolin hollow fibre membranes was also enhanced after modification. Excellent water vapor flux performance was obtained for the modified metakaolin hollow fibre membrane prepared at the sintering temperature of $1200^{\circ} \mathrm{C}$. It was revealed that the membrane hydrophobicity and membrane pore size are the main factors in MD application. A future study on the membrane thermal stability and treatment on the contaminated wastewater will be studied.

\section{ACKNOWLEDGEMENT}

The authors would like to acknowledge the financial support from the Ministry of Education Malaysia under the Higher Institution Centre of Excellence Scheme (Project Number: R.J090301.7846.4J192), and also Universiti Teknologi Malaysia under the Transdisciplinary Research Grant (Project number: Q.J130000.3509.05G75), Malaysia Research University Network (MRUN) Grant (Project number: R.J130000.7809.4L867), and UTM Fund (Project number: R.J130000.7746.4J309).

\section{REFERENCES}

[1] M. Mulder. 1996. Basic Principles of Membrane Technology. Netherland: Springer.

[2] S. Munirasu, F. Banat, A. A. Durrani, M. A. Haija. 2017. Intrinsically superhydrophobic PVDF membrane by phase inversion for membrane distillation. Desalination, 417, 77-86.

[3] H. Zhang, M. Liu, D. Sun, B. Li, P. Li. 2016. Evaluation of commercial PTFE membranes for desalination of brine water through vacuum membrane distillation. Chemical Engineering and Processing: Process Intensification, 110, 52-63.

[4] A. Criscuoli, P. Bafaro, E. Drioli. 2013. Vacuum membrane distillation for purifying waters containing arsenic. Desalination, 323, 17-21.

[5] A. Alkhudhiri, N. Darwish, N. Hilal. 2012. Membrane distillation: A comprehensive review. Desalination, 287, 2-18.

[6] M. A. Abdulhameed, M. H. D. Othman, A. F. Ismail, T. Matsuura, Z Harun, M. A. Rahman, M. H. Puteh, J. Jaafar, M. Rezaei, S. K. Hubadillah. 2017. Carbon dioxide capture using a superhydrophobic ceramic hollow fibre membrane for gas-liquid contacting process. Journal of Cleaner Production. 140, Part 3, 1731-1738.

[7] J. Gu, C. Ren, X. Zong, C. Chen, L. Winnubst. 2016. Preparation of alumina membranes comprising a thin separation layer and a support with straight open pores for water desalination. Ceramics International, 42, 12427-12434.

[8] S. K. Hubadillah, M. H. D. Othman, Z. Harun, A. F. Ismail, M. A. Rahman, J. Jaafar, S. M. Jamil, N. H. Mohtor. 2017. Superhydrophilic, low cost kaolin-based hollow fibre membranes for efficient oilywastewater separation. Materials Letters, 191, 119-122.

[9] S. R. Krajewski, W. Kujawski, M. Bukowska, C. Picard, A. Larbot, Application of fluoroalkylsilanes (FAS) grafted ceramic membranes in membrane distillation process of $\mathrm{NaCl}$ solutions. 2006. Journal of Membrane Science, 281, 253-259.

[10] C.-Y. Huang, C.-C. Ko, L.-H. Chen, C.-T. Huang, K.-L. Tung, Y.-C. Liao. 2016. A simple coating method to prepare superhydrophobic layers on ceramic alumina for vacuum membrane distillation. Separation and Purification Technology, 198, 79-86.

[11] S. Khemakhem, R. B. Amar. 2011. Grafting of fluoroalkylsilanes on microfiltration Tunisian clay membrane. Ceramics International, 37, 3323-3328.

[12] S. K. Hubadillah, M. H. D. Othman, Z. Harun, A. F. Ismail, Y. Iwamoto, S. Honda, M. A. Rahman, J. Jaafar, P. Gani, M. N. Mohd Sokri. 2016. Effect of fabrication parameters on physical properties of metakaolinbased ceramic hollow fibre membrane (CHFM). Ceramics International, 42, 15547-15558.

[13] Z. Harun, H. S. K., S. Hasan, M. Z. Yunos. 2014. Effect of thermodynamic properties on porosity of ceramic membrane prepared by phase inversion, Applied Mechanics and Materials, 575, 31-35.

[14] S. K. Hubadillah, Z. Harun, M. H. D. Othman, A. F. Ismail, W. N. W. Salleh, H. Basri, M. Z. Yunos, P. Gani. 2016. Preparation and characterization of low cost porous ceramic membrane support from kaolin using phase inversion/sintering technique for gas separation: Effect of kaolin content and non-solvent coagulant bath. Chemical Engineering Research and Design, 112, 24-35.

[15] Y.-F. Chen, M.-C. Wang, M.-H. Hon. 2004. Phase transformation and growth of mullite in kaolin ceramics. Journal of the European Ceramic Society, 24, 2389-2397.

[16] D. Kim, N. M. Pugno, S. Ryu. 2016. Wetting theory for small droplets on textured solid surfaces. Scientific Reports, 6, 37813

[17] E. Drioli, A. Ali, S. Simone, F. Macedonio, S. A. Al-Jlil, F. S. Al Shabonah, H. S. Al-Romaih, O. Al-Harbi, A. Figoli, A. Criscuoli. 2013. Novel PVDF hollow fiber membranes for vacuum and direct contact membrane distillation applications. Separation and Purification Technology, 115, 27-38

[18] N. M. Mokhtar, W. J. Lau, B. C. Ng, A. F. Ismail, D. Veerasamy. 2015 Preparation and characterization of PVDF membranes incorporated with different additives for dyeing solution treatment using membrane distillation. Desalination and Water Treatment. 56, 1999-2012.

[19] H. Zhu, H. Wang, F. Wang, Y. Guo, H. Zhang, J. Chen. 2013 Preparation and properties of PTFE hollow fiber membranes for desalination through vacuum membrane distillation, Journal of Membrane Science. 446, 145-153.

[20] J.-W. Wang, L. Li, J.-W. Zhang, X. Xu, C.-S. Chen. 2016. ß-Sialon ceramic hollow fiber membranes with high strength and low thermal conductivity for membrane distillation. Journal of the European Ceramic Society, 36, 59-65. 